\title{
Social Media Affordances and Sequential Use to Engage Clients During the Sales Process
}

\author{
Matthew S. Weber \\ University of Minnesota \\ msw@,umn.edu
}

\author{
Muge Haseki \\ University of Pennsylvania \\ mhaseki@law.upenn.edu
}

\begin{abstract}
Social media has changed the ways salespeople communicate and build relationships with clients. This study explores how social media are integrated into the communication repertoires of sellers using an affordances framework. Based on data from a large multinational corporation, seller strategies used to build and develop relationships with customers are analyzed. The findings reveal that employees strategically select media that allow for common affordances in order to build stronger client relationships. The discussion outlines practical implications for managers, and aligns the process of social media selection with the sales cycle based on capabilities afforded by various media choices.
\end{abstract}

\section{Introduction}

Salespeople (or sellers) within organizations use social media to create new business opportunities and to strengthen relationships with clients [1]. The process by which sellers communicate with and establish relationships with clients has evolved over the past decade, particularly for large multinational organizations that rely on information communication technology (ICT) to manage client engagement [2]. In addition to staples of workplace communication such as email and telephone, the increasing popularity of social media provides new options for actively gathering information about and communicating with prospective clients $[1,3]$, and for generating engagement with clients [4].

Large multinational organizations have invested significant resources into developing new ICTs in order to keep pace with changing sales practices. And yet organizations remain unsure about the impact of new forms of ICT on organizational effectiveness, particularly with regard to external communication with clients [1]. In turn, recent studies investigate how organizations cultivate relationships with external stakeholders via social media tools $[5,6]$, but the impact of social media on client communication is still unclear as is the process by which sellers utilize specific social media [7]. Given the significant financial investment by organizations, and the lack of empirical clarity with regards to the impact of social media use, it is clear that further work is needed to understand the impact of ICTs.

In order to better understand how certain social media are chosen and utilized, this study examines how sellers use affordances of social media to attract and engage clients. Prior research demonstrated that the use of multiple ICTs enhances organizational relationships [8]. Also, sellers have a clear and significant impact on the success of an organization in maintaining profitability through sales [9]. A second goal is to provide insight into how sellers use multiple ICTs to develop relationships with clients.

\section{Organizations, Social Media and Client Communication}

As the use of proprietary and public social media in large multinational organizations grows, organizations are focusing on how social media tools can be utilized by sellers as part of the sales process. Social media have made communication more instantaneous by allowing sellers to respond faster to communication from clients, demonstrating the perceived importance of social media as an external communication tool [10]. External engagement via social media is beneficial because interactions may result in increased connectedness with clients [11].

Yet social media is not the only tool available to sellers; rather most large multinational organizations provide sellers with a repertoire of ICTs from which the seller must select the most appropriate tool to engage with clients. As a result of the trend towards availability of multiple communication tools, prior research establishes that organizational members often use multiple media to communicate with others at work [12], but has not explicitly focused on how communication tools are selected. Building on prior research [13], we use an affordances lens to examine the use of multiple media in external communication processes (e.g. the sales process). 


\subsection{Affordances of Social Media in Organizations}

Social media is a broad class of Internet-based ICTs that enable social connectedness amongst individuals. Examples of social media utilized in organizations include LinkedIn and Twitter. Large multinational organizations often purchase enterprise social networking systems from third-party vendors, such as Jive, that create custom social networking sites for internal organization use, or develop proprietary systems, such as Cisco's Quad, which is an internal collaboration platform. Internal systems offer increased data security and control of access. Following Treem and Leonardi [13], we refer to social media utilized exclusively by organizations as enterprise social media. Employees often are able to utilize both proprietary internal systems and publicly available social media when communicating externally with customers. Employees must therefore choose amongst a suite of social media options in order to communication - both internally and externally - as they strive to address a wide array of organizational goals [14]. In the context of the sales process, it is thus important to understand the connections between the affordances of a given technology, and the way in which the technology is selected and used for a given purpose by a seller.

To that end, recent research has prioritized an affordances perspective [15]. An affordances lens provides a framework for information systems scholars to better understand the characteristics of social media that lead users to select a given technology [16]. Moreover, an affordances perspective also points to the basic building blocks of social media use, helping to fill a key gap noted by others studying the use of social technology in information systems [17].

The affordance perspective focuses on how and why individuals use technology differently from one another, putting the same technology to different uses. Affordances are the result of a users' engagement with a technology, goals of use, and the material features of the technology itself. Affordances have been used to explore the interaction between individuals, organizations and technology, examining both the nature of the technological artifact, and the use of that artifact in context. Boyd [18] noted that social media affords users persistence (content is maintained), replicability (easily duplicated), scalability (viewable and extendable) and searchability (searchable content). Despite these general categorizations, specific affordances that a user is able to realize are the result of the interaction between the user, the design of the technology, and the use context.

Underlying the affordances perspective, there is a tension between the intended use of a technology (as it was designed) and the way a user chooses to implement a technological artifact. As Faraj and Azad [19] note, an "Affordance is often realized via the enactment of several mutuality relations between the technology artifact and the actor" (p. 254). For instance, enterprise social media are used for both internal and external communication. The affordance that is realized by the user will occur as a compromise between what a given technology is designed for and the user's end use of that tool.

\subsection{Enterprise Social Media and External Relationships}

Gibbs, Rozaidi and Eisenberg [20] introduce strategic affordances to explain that employees may selectively utilize the features of social media to either conceal or share knowledge, dependent on the context. In a system of ICT use and information exchange, the manner by which employees utilize strategic affordances is central in their ability to establish and maintain external relationships. For instance, the searching affordance of LinkedIn or Twitter allows organizational members to search for content relevant to a particular need, access the content and then transform it (via reposting) into relevant information for client interactions [21]. The relevance of the reposted content depends on the degree to which existing knowledge can be utilized and whether the relevant discussions in the social media can be identified.

The context of content creation via social media is critical in determining the manner in which clients perceive content [22]. Sellers must leverage the affordance to strategically utilize social media to reach out to customers. While some content may contain interesting and useful information, other information is often of little value, or even distracting. A recent study demonstrated that adequate content management strategies support building relationships between organizations and consumers [23]. Given the increasing important of social media in the selling process, and the critical role of strategic affordances in sales, it is clear that more research is needed in this area. Thus, this topic is examined through the following research question: RQ1: How do organizational members utilize the affordances of social media to strategically engage clients? 


\subsection{Enterprise Social Media and External Relationships}

Individual technologies afford sellers with particular capabilities, depending on the nature of the technology, the goals of the user and the context of use. In day-to-day work, sellers within organizations must navigate a multiplex of media options, each with a different set of affordances, in order to accomplish specific goals. Sellers must navigate how to leverage social media to complement traditional channels. As new ICTs continue to gain dominance, the ongoing challenge is to continue adapting the traditional marketing mix [3].

From a networked systems perspective, Haythornthwaite [24] proposed media multiplexity theory, which predicts that stronger relationships are supported by the use of more media channels, whereas weaker relationships tend to enact communication via a smaller number of channels. In other words, a relationship with a high degree of media multiplexity will tend to have a stronger relational tie because the greater number of media channels that are utilized allows for a higher degree of influence and relational coordination. In complement, sequential use of media is common in organizations [25]. Sequential media use refers to the successive use of distinct communication media use for the same purposes. Employees often use multiple media in sequence to communicate with others, and strategically combine media to serve their goals and to fit a given context [26], echoing the earlier notion of strategic affordances. Sequential media use may help relationships develop, and can be more persuasive than the use of one channel.

\subsection{Driving Relational Outcomes}

In all, sequential and multiplex media use should help sellers to gather information about external partners and to improve sales effectiveness. Initial communication often occurs virtually, with subsequent interactions building to face-to-face interactions. Research has shown that successful relationships maintained via technology depend on the use of different ICTs to enhance the breadth and depth of their communication [27]. Variety of communication channels may generate more flexibility and responsiveness in creating relationship building strategies [28], although the exact impact is not well known.

Thus, media multiplexity should enhance relationships between sellers and clients, which in turn can improve sales outcomes. For instance, utilizing email and phone in conjunction LinkedIn and Twitter should enable sellers to exert greater influence on clients. Sellers in large multinational organizations face the challenge of managing multiple communication channels, with the goal of improving client relationships while reducing confusion and noise. That said, the connection between sequential media use and sales outcomes is not well understood, nor is that way in which media are selected in a sequential process. Thus, through appropriation, sellers identify the unique affordances of a new communication tool [29]. Sellers must select which communication tools to use, and in what order, to build relationships in a multi-channel environment. This is explored as follows: RQ2: How are multiple ICTs used by sellers to affect relational outcomes?

In sum, the two research questions outlined in this study provide a framework for understanding ICT use for external engagement in large multinational organizations. We posit that affordances guide the strategic use of social ICTs, but seek to better understand whether ICT use is sequential or multiplex in nature.

\section{Methods}

Interactions within Beta Corp. (a pseudonym), a large multinational corporation, were analyzed in order to understand how sellers select ICTs to engage in communication with clients, and how sellers select ICT affordances. Data in this study represent an indepth case study of technology use at a specific organization; this approach allows for an in-depth investigation of the relevant variables [30], and further allows the researchers to assess relationships between variables that might be missed utilizing broader methodologies [31].

\subsection{Research Setting}

Data were collected from the sales division of Beta Corp.. Beta Corp. has more than 75,000 employees distributed globally; the sales division consists of more than 3,000 sellers. The company is structured as a networked organizational form; although there is an established hierarchy, divisions function as independent businesses comprised of modular subdivisions. Sellers work in crossfunctional teams, comprised of managers, sales representatives, analysts and consultants from other divisions, and business partners outside of Beta Corp. 
Sellers at Beta Corp. utilize a wide range of ICTs to communicate internally and externally. The company has also developed proprietary systems including an instant messaging system (QuickChat), a knowledge management tool (KnowShare), and an enterprise social media platform (ConnectHub) (all system names are pseudonyms). The researchers studied the ways in which individuals within the division utilized ICTs to maintain relationships with clients. Sellers were encouraged to use externally developed tools including Twitter and LinkedIn. External tools are an important component of the sales process as they facilitate communication with clients in a "natural" environment. Sellers focus on communication with clients and business partners to generate new leads, maintain existing business relationships, and to develop and close business deals. Beta Corp. is an ideal setting for research given the variety of communication tools used by sellers, and the focus of the sales division on engagement with customers via technology. Moreover, the size of the division provides a large enough sample to capture sufficient variance in use cases.

\subsection{Data Collection}

Data collection for this study took place from 2012 to 2015. The researchers conducted ten background interviews with sellers in order to inform survey design. A 30-minute survey was distributed to 1651 sellers within the sales division. Of those surveyed, 635 responded yielding a 39 percent response rate. All responses were deidentified upon collection. In this study, the survey was used for descriptive purposes. Subsequently, between in mid2012 another 25 semi-structured interviews lasting approximately 45 minutes each were conducted in order to garner further insight about multiple media use of organizational members and explore our research question on multiple media use and relationship building. The interview included questions about ICTs used for identifying clients, for initiating contacting and engaging with clients, and building relationships. Interviewers engaged with sellers to assess the use of multiple media. Interviews were recorded and transcribed. In addition to the above, the lead researcher spent 4 weeks conducting observations in two of the primary sales centers in the summer of 2013, one in northern Europe, and the other in the Midwestern United States, with another follow-up period of two weeks in mid-2015. The researcher was able to observe 2 teams in each location, generating more than 100 pages of field notes, which were used to reinforce findings from the survey and interviews. The approach of mixing interviews with observations follows prior research on affordances; the survey was used as a key data point to contextualize the research [13].

\subsection{Data analysis}

The results of the survey were used to understand the context of technology use by sellers within Beta Corp. Researchers used an inductive qualitative approach, reading, and re-reading the interview transcripts throughout the data collection process, and iteratively developing a coding scheme [32]. During the initial coding pass, coders identified engagement with specific external clients, instances where technology use was discussed, and specific mention of relational outcomes.

Initial iteration of coding focused on identifying specific instances of realized affordances; given our expectation of certain affordances in the context of enterprise social networking, we specifically sought instances of affordances such as editability and visibility, but also sought to identify emergent affordances. Broad sections of text were coded to identify instances of multiplexity and sequential media use, looking at media use for (a) persuasive communication with clients and (b) relationship development with clients, with codes created to capture each aspect [33]. NVivo 9 was used for coding, and inter-rater agreement on content topics was within acceptable ranges, based on Cohen's kappa $(\mathrm{k}=0.9)[34]$.

The second step of analysis focused on axial coding in order to better understand the relationship between realized affordances and multiplex technology use. This stage of coding focused on the connection between (1) the way affordances were realized by specific sellers, (2) the subsequent multiplex / sequential use of technology, and finally (3) the relational outcomes resulting from engagement with clients. In the concluding section of our findings, these three sections of analysis are woven together to reveal a stepwise process by which multiplex technology use is engaged to establish and develop relationships between sellers and clients.

\section{Results}

\subsection{Assessment of Media Use at Beta Corp.}

Descriptively, the survey findings provide useful context for understanding media multiplexity within Beta Corp. First off, the demographics reveal a broad spectrum of sellers (36 percent female; 64 percent male) across age groups (54 percent were between 
25- and 35-years-old, and 12 percent were at least 47years-old). Turnover within the organization is relatively low; only 17 percent have been with the company less than one year.

Traditional media remain important at Beta Corp. In terms of technology use, sellers rank email as the most important tool for getting work done, following by phone, QuickChat, web search (Google), face-to-face communication, mobile phone, ConnectHub and KnowShare, ranked in order. Survey results further indicated that multiplexity is common within the organization. For instance, when communicating externally, 40 percent use QuickChat once a day, and ConnectHub is similarly used by 20 percent on a daily basis. Professional social networking sites (e.g. LinkedIn and Xing) and microblogs such as Twitter are also used frequently (34 percent and 25 percent, respectively, report using each at least once a week). The initial findings underscore the fact that multiple media are used throughout the sales process to engage with potential customers; the survey was inconclusive with regards to sequential use of media in the sales process.

\subsection{Leveraging Multiple Media for Strategic Relationship Building}

Our first research question asked how sellers use social media to strategically engage with clients. Data reveal that strategic engagement in the sales process occurs through a mix of searching and strategic visibility via social media and traditional tools.

The interviews revealed that engagement with clients occurs in sequential stages at Beta Corp. As observed, sellers in the sales division initially use tools such as LinkedIn and Twitter to search for resources and reference information about clients. Initial contact is often made via social media channels and sequentially email is then utilized to engaged. Phone or face-to-face meetings occur in the later stages of engagement. During the search phase, sellers look for personal information about a customer on LinkedIn or Twitter, focusing on interests, common bonds such as alma maters, or common friends; this information allows sellers to create an initial common bond upon which conversation can build. Kovacs [35] reported that identifying common interests between sellers and clients is imperative to effective relationship building. Sellers at Beta Corp. refer to this process as "data mining" and "customer contact lining." One seller observed: "You're doing the detective work as a hunter to find content to buy contact." Moreover, the identification of common interests is clearly facilitated by the affordances of the selected media.

Reference information about clients is useful when sellers do not have an established relationship with a client. One seller said, "I follow [the client] more than they follow me. I try to engage them in things that interest them." Another seller noted:

"So a lot of the times, I don't have a running conversation with the client and I follow them on Twitter. I send them tweets. I try to invite them in the marketing campaign where I have weekly trivia questions and I send prizes."

These examples illustrate how sellers strategically utilize multiple media sequentially to initiate a new conversation with clients, first leveraging the visibility of others that is afforded by social media to search for information, and sequentially utilizing direct communication afforded by traditional media such as email, or direct messaging options afforded by platforms such as Twitter.

From an affordances perspective, there were multiple instances whereby sellers created association with clients by connecting and engaging via shared content on Twitter and LinkedIn. Persistence of such content increases visibility to clients while diminishing. Once a client is engaged, however, the sequence of media use leads the seller to engage over existing tools such as email, phone calls, or QuickChat. The sequence of interaction is seen in the following example:

"When they see what I'm communicating through my webpage, they call me and say [Oh, I see you have a new solution on the market] or [I have this version of the product. Can I get the newest one?]"

The prior sequence is common among sellers at Beta. Multiplexity occurs specifically between social media and traditional channels; communication often occurs simultaneously via channels such as Twitter and LinkedIn, with an accompanying email sent simultaneously. One seller indicated: "As much as you tweet..., you also need to make as many phone calls." Similarly, another suggested, "I think the challenge of a seller is to ... find the right balance [of all the ways of communicating]," suggesting that multiple media are strategically used in concert to initiate contact. Nearly every seller interviewed indicated that social media tools are "supplementary" and they need to put a personal "face" into the relationship, even if that occurs virtually. As the above illustrate, affordances of social media are combined with traditional communication tools in strengthening client relationships. Multiplexity is advantageous in the initial contact, but the communication path ultimately leads toward more 
sequential communication, as the seller shifts to oneon-one communication via email and phone.

\subsection{Multiple Media Use and Relational Outcomes}

Our second research question asked how multiple media are used to drive beyond initial contact in order to affect relational outcomes. Data revealed that multiple media use has the potential to improve relational outcomes by enabling 1) identification of opportunities, 2) building relationships, and 3) garnering credibility.

4.3.1. Identification of opportunities. Social media allow sellers to identify clients through association. For instance, sellers can add professional groups on LinkedIn to expand their network and discover potential clients. One seller noted that it is important to "put not only a sizable network together, but a strategic network, where it really helps and enables you to penetrate [customer] accounts." In another example, a seller associated with competitors:

"The other thing that I've done that's been clever is I added a bunch of competitors in my LinkedIn. Some of them have already added customers. So I could find customers via my competitors to connect with."

Thus, the strategic implementation of the associative affordance of social media enables the expansion of one's network.

4.3.2. Building relationships. Multiple media are often used in concert (multiplexity) to build a relationship. For instance, once a lead is identified, a seller will engage via multiple channels. As one seller explained: "I'm going to send my details via e-mail, you will also find a link to my personal webpage where you can find my phone number and a [QuickChat]" or "Hey look! I've got my Twitter ID in my email signature. Why wouldn't you follow me?" Multiplexity of media affords reinforcement of a common message; by aligning common affordance of different media, a seller is able to strengthen attempts to engage clients.

Engaging a building a presence via social media necessitates maintenance and monitoring [36]. One seller illustrated how his online content helped him engage his existing content: "When they see what I'm communicating through [social media], they call me and say 'Oh, I see you have a new solution on the market' or 'I have [and old] version of the product. Can I get the newest one?" As Hallahan [37] suggested "responsive discourse" must be "timely, pertinent, and authentic" (p. 53) so that clients would be willing to maintain relationship.

The timeliness of social media demands that sellers move beyond persistence, and leverage the afforded immediacy of social media. As an affordance, immediacy is the real-time capacity of social media, which requires that organizational members maintain up-to-date content in order to stay engaged. Immediacy affords users the ability to receive up-to-date content posted to a platform.

\subsubsection{Building Credibility.}

Hallahan [37] found that users seek personalized and customized information; greater personalization drives satisfaction. In the sales context, this personalization appears to improve credibility, as a seller demonstrated:

[My online presence is] how I want to present myself to my customers or people interested in what I do on a daily basis. So, in my opinion it's my business card. I want to have ownership of it. If you want to kind of target a specific market, I would like to use my own content, and make it really my webpage and not another webpage that's similar to other hundreds of webpages out there.

Building a trusting relationship is key to establishing a bond with a client. Park and Reber [38] noted that trust is measured by "the conservation of visitors and usefulness of information" (p. 410). Multiple sellers noted that when a customer finds client relevant, $=\mathrm{a}$ next step is direct engagement from the client. As one seller puts it: "[The client] can look at my profile and quickly determine that what I'm sharing with them is something that I can assist them with and showing my credibility as a good resource for [Beta Corp.]." Another seller suggested: "If you post good content, [the customer] will see that in the news feed. I think you have some credibility and this is initial trust you build with the customers." In this way, the relevance and engagement are translated into a perception of credibility and trust. The use of multiple forms of social media builds the reputation of a seller, so the seller is known without having met the client directly.

\section{Discussion}

\subsection{Summary of implications}

In sum, the findings from this study demonstrate that social media drive are used selectively during the sales process when the affordances line up with a particular stage in the sales cycle. Moreover, social 
media are generally used in a multiplex manner, to complement traditional media. Beyond that, however, multiple forms of media are used in a sequential manner to manage the overall sales process. The following discussion further analyzes practical and theoretical implications of these findings.

This study focuses on the utilization of a variety of ICTs by sellers, through their realization of the affordances of each respective form of media. As the findings from the analysis of media use at Beta illustrate, multiplex and sequential media use are central to the communication process between seller and clients. In particular, sequential media use is critical for searching out new clients and building relationships that may eventually lead to an increase in sales. Table 1 provides a summary of the various types of affordances utilized by sellers in this process, including previously identified affordances of editability, persistence, association and visibility, as well as immediacy, as identified in this study. The table illustrates the types of affordances used within Beta Corp., and also illustrates the multiple media forms used to engage a given affordances, and to interact with clients. The final column of the table connects technology use to relational outcomes.

\subsection{Selecting Affordances for Strategic Relationship Building}

From a practical perspective, the findings identify a clear path for engaging social media as part of the seller's communication repertoire in order to build and maintain relationships with potential clients. Others have suggested a repertoire approach to social media use [39], but this work extends that lens to the specific context of external organizational communication. The findings suggest that sellers should consider media use as a repertoire. Our findings suggest, for instance, that training in organizations should focus on sequential use of different communication channels in addition to technology-specific trainings. For example, the use of the search affordance across social media enables the formation of common bonds externally, and strengthens relational outcomes. Managers, however, must be careful to encourage the use of search across multiple media when engaging in search. Utilizing multiple media for search provides more accurate and reliable information for engaging with clients.

Indeed, theoretically, observations reveal that multiplex media use occurs in a stepwise process as sellers engage clients. First, sellers search for clients, and then they seek to engage and build a relationship. Next, they develop messages and strategically seek to engage with clients. Finally, sellers seek to build tie strength and maintain the relationship. This process of sequential media use is explicated in the following.

5.2.1. Searching for Clients. From an affordance perspective, sellers seek out clients by realizing the visibility and persistence afforded by social media. Information available on social media makes it easier for sellers to identify key external customers through search (e.g. search by company or search by name on LinkedIn.com). Sellers use these affordances to look up the company and add people to their networks.

5.2.2. Initiating Contact with Clients. Sellers keep track of their existing and/or potential clients, business partners, competitors on LinkedIn and Twitter, and utilize search to learn more about their thoughts, questions, interests, and use that content in future conversations. Though search, and by the practical act of following clients, sellers can identify what's really important to that organization and keep track of the intentions and behaviors of the clients.

5.2.3. Engaging with Clients. Through the association and immediacy affordances of social media, sellers can attract potential customers' notice through striking messages. For instance, one of the sellers said, "I'll write silly tweets. Well, so many tweets are boring. So I've done some with Children's Nursery Rhymes. I've done some -- let me think of some examples here. Let's see, 'Hickory, Dickory', Doc the server ran up the cost." Such behavior helps to maintain a presence in front of potential clients.

5.2.4. Strengthening Ties. Visibility of users' information on social media allows sellers to create personal messages, which can be used to support initial conversations. One seller illustrated how he utilizes this affordance to create personal messages: "So for example my background is in physics and recently I found one of my clients is reading a lot about quantum mechanics. So when I called him, I was like, I saw your Twitter feed. I have a degree in physics. Do you want to talk about it?"

5.2.5. Gathering Information and Contextualizing. Again engaging via immediacy, sellers use social media tools such as LinkedIn and Twitter to inform others about market related news such as interesting articles webinars. Ledford [40] suggested that it is important for communicators to balance the continuous delivery of information to maintain an interested audience and the information overload, as illustrated by example in Table 1 .

The table further shows the corresponding information communication technology utilized when 
engaging in behavior associated with a given affordance. These technologies are examples, as the specific technology used at any given time may fluctuate depending on the intentions of the user. This iterative process illustrates how social media affordances are engaged in the sales process, and points to a process whereby future iterations of social media can be layered into the system selectively to build external bonds. also prove to be central in educating about best practices. Informal educational opportunities, such as 'lunch and learns,' or informal coffees, provide sellers with an opportunity to talk about the use of social media in practice. In aggregate, the findings point ways in which organizations can enhance the use of social media.

Table 1. Summary of Central Affordances Realized in Beta Corp

\begin{tabular}{|l|l|l|l|}
\hline Affordance & \multicolumn{1}{|c|}{ Example } & \multicolumn{1}{|c|}{ Communication Tools } & \multicolumn{1}{|c|}{ Relational Outcome } \\
\hline Visibility & $\begin{array}{l}\text { "So the more you tweet, the more you message, } \\
\text { the more likely you are to have your message fall } \\
\text { upon the correct audience." }\end{array}$ & $\begin{array}{l}\text { Email, Web page, } \\
\text { Twitter, LinkedIn, } \\
\text { Smartphone }\end{array}$ & $\begin{array}{l}\text { Improved perception by client, } \\
\text { increased social presence, identifying } \\
\text { opportunities, improved customer } \\
\text { loyalty }\end{array}$ \\
\hline Editability & $\begin{array}{l}\text { "I would share only my professional background } \\
\text { or about my education, where I'm coming from, } \\
\text { what I am responsible for and what my strength." }\end{array}$ & $\begin{array}{l}\text { Email, Web page, } \\
\text { Twitter, Xing, LinkedIn }\end{array}$ & $\begin{array}{l}\text { Improved perception by client, } \\
\text { Identifying opportunities }\end{array}$ \\
\hline Immediacy & $\begin{array}{l}\text { "I try to pick up current articles, more like } \\
\text { industry turned articles that are generally pretty } \\
\text { interesting... I'm trying to avoid feeding out a } \\
\text { bunch of generic information because that's just } \\
\text { like throwing a dart at the wall." }\end{array}$ & $\begin{array}{l}\text { Web page, Twitter, Xing, } \\
\text { LinkedIn }\end{array}$ & $\begin{array}{l}\text { Improved perception by client, } \\
\text { Increased presence, Identifying new } \\
\text { opportunities, increased customer } \\
\text { loyalty }\end{array}$ \\
\hline Association & $\begin{array}{l}\text { "Number one, you have to actually get the people } \\
\text { to follow you and then once they follow you, you } \\
\text { have to have meaningful content to keep them." }\end{array}$ & $\begin{array}{l}\text { Twitter, LinkedIn } \\
\text { Person-to-person); Web } \\
\text { page, Twitter, LinkedIn }\end{array}$ & $\begin{array}{l}\text { Identifying opportunities, Building trust } \\
\text { and expertise }\end{array}$ \\
\hline Searchability & $\begin{array}{l}\text { "If I have contact information or if there is } \\
\text { somebody that I've worked with in the past, then, } \\
\text { I will search for them on LinkedIn." }\end{array}$ & $\begin{array}{l}\text { Twitter, LinkedIn } \\
\text { impressions }\end{array}$ & $\begin{array}{l}\text { Identifying opportunities, increased } \\
\text { impres }\end{array}$ \\
\hline
\end{tabular}

\subsubsection{An aggregate model of the sales process and} social media. The above stepwise model suggests an alignment of the utilization of social media affordance with the sales process. Indeed, others have suggested that the strategic use of social media may help to improve the probability of moving a lead from understanding and approaching the customer, through to the generation of new business [22].

Social media may prove advantageous for sales professionals; the utilization of the theoretical hook of affordances, however, provides a mechanism for aligning social media utilization with the sales process.

At each key phase of the sales process, the actualization of particular affordances of social media connects media use to the sales process. Notably, affordances are not definitive in nature; rather, the realization of a particular affordance depends on the way an individual chooses to utilize the particular features of a technology in a given context. Thus, managers can engage in training and coaching to help sellers to be more aware of the interconnectedness of various social media platforms, informal learning will

\section{Theoretical Implications}

There are a number of important theoretical implications. Broadly, prior research has pointed to a need to better understand the characteristics of social media that lead to use in certain contexts (e.g. via affordances) [16]. Our findings establish a sequential process of media use in external communication based on the degree to which particular technologies afford engagement with clients, with higher levels of engagement needed later in the process.

Interview data revealed that sellers have strategically integrated social media tools to their existing communication repertoires to build and maintain relationships with customers. Utilizing the affordances of social media such as manual search [21], and visibility to others [13], sellers sequentially select media to build and to strengthen their external relationships. This study shows what combinations of features of existing communication and social media tools allow sellers to engage with clients in a credible and personalized fashion, which was previously challenging. Besides, sequential use of regular phone 
calls and QuickChat are integral in increasing presence. Similarly, the visibility affordance helps sellers increase their social presence as well as improve trust and perceived expertise.

From a theoretical perspective, common affordances are realized as media are sequentially utilized; this suggests that common affordances lead to the strategic selection of multiple media. Sellers engaged in communication with clients look to search for information, for instance, by selecting a number of particular media platforms that each allow for search, but also provide access to distinct information (or reinforcing information). In another light, it is also significant, as revealed in the findings, that instances of sequential media use trump instances of multiplexity. Prior work on multiplexity has focused on internal communication patterns, and indeed this research reinforces that multiplexity is less of a factor in external communication (although multiplexity may occur as internal communication occurs in synchronicity with external communication). Rather, sequential media use is shown to be more central to external processes.

\subsection{Limitations}

There are a number of limitations to this article that may impact the findings. First, data are drawn from a case study, and thus it is challenging to generalize the findings beyond the context of large multinational organizations. Moreover, the findings are based on a qualitative analysis of interviews and descriptive analysis of a survey. Beyond that, the focus on internal ICTs that are proprietary to the organization means that the findings are restricted, to a certain extent, to the nature of the tools used by organizations. In short, these findings provide a broad map for understand affordances and sequential media use, but the context of use matters.

\subsection{Future Research}

This work represents a first step in addressing the connections between social media affordances, media choice and external processes. Future research should work to build on the findings from this article, focusing specifically on moving from a qualitative analysis of social media affordances in a selling context to a quantitative analysis of the impact of media choice on selling outcomes. As others have noted [1], there is a need to better understand the impact of media choice on sales outcomes, especially in the broader context of systems of technology and information use. Moreover, there is a clear need for longitudinal research in order to understand the causal impact of social media use.

\section{References}

[1] Rodriguez, M., Peterson, R.M., and Krishnan, V.: 'Social media's influence on business-to-business sales performance', Journal of Personal Selling \& Sales Management, 2012, 32, (3), pp. 365-378

[2] Cho, S., and Huh, J.: 'Content analysis of corporate blogs as a relationship management tool', Corporate Communications: An International Journal, 2010, 15, (1), pp. $30-48$

[3] Mangold, W.G., and Faulds, D.J.: 'Social media: The new hybrid element of the promotion mix', Business Horizons, 2009, 52, (4), pp. 357-365

[4] Ang, L.: 'Community relationship management and social media', Journal of Database Marketing \& Customer Strategy Management, 2011, 18, (1), pp. 31-38

[5] Bortree, D.S., and Seltzer, T.: 'Dialogic strategies and outcomes: An analysis of environmental advocacy groups' Facebook profiles', Public Relations Review, 2009, 35, (3), pp. 317-319

[6] Waters, R.D., Burnett, E., Lamm, A., and Lucas, J.: 'Engaging stakeholders through social networking: How nonprofit organizations are using Facebook', Public Relations Review, 2009, 35, (2), pp. 102-106

[7] DiStaso, M.W., McCorkindale, T., and Wright, D.K.: 'How public relations executives perceive and measure the impact of social media in their organizations', Public Relations Review, 2011, 37, (3), pp. 325-328

[8] Eyrich, N., Padman, M.L., and Sweetser, K.D.: 'PR practitioners' use of social media tools and communication technology', Public relations review, 2008, 34, (4), 412-414

[9] Fu, F.Q.: 'Effects of Salesperson Experience, Age, and Goal Setting on New Product Performance Trajectory: A Growth Curve Modeling Approach', Journal of Marketing Theory and Practice, 2009, 17, (1), pp. 7-20

[10] Wright, D.K., and Hinson, M.D.: 'How blogs and social media are changing public relations and the way it is practiced', Public Relations Journal, 2008, 2, (2), pp. 1-21

[11] Heller Baird, C., and Parasnis, G.: 'From social media to social customer relationship management', Strategy \& Leadership, 2011, 39, (5), pp. 30-37

[12] Turner, J.W., and Reinsch, N.L.J.: 'The Business Communicator as Presence Allocator: Multicommunicating, Equivocality, and Status at Work', Journal of Business Communication, 2007, 44, (1), 36-58

[13] Treem, J.W., and Leonardi, P.M.: 'Social media use in organizations: Exploring the affordances of visibility, editability, persistence, and association', Communication yearbook, 2012, 36, pp. 143-189 
[14] Moore, J.N., Raymond, M.A., and Hopkins, C.D.: 'Social Selling: A Comparison of Social Media Usage Across Process Stage, Markets, and Sales Job Functions', Journal of Marketing Theory and Practice, 2015, 23, (1), pp. $1-20$

[15] Majchrzak, A., Faraj, S., Kane, G.C., and Azad, B.: 'The contradictory influence of social media affordances on online communal knowledge sharing', Journal of Computer-Mediated Communication, 2013, 19, (1), pp. 3855

[16] Mathiesen, P., Bandara, W., and Watson, J.: 'The affordances of social technology: a BPM perspective', in Editor (Ed.)^(Eds.): 'Book The affordances of social technology: a BPM perspective' (Association of Information Systems-AIS, 2013, edn.), pp.

[17] Kietzmann, J.H., Silvestre, B.S., McCarthy, I.P., and Pitt, L.F.: 'Unpacking the social media phenomenon: towards a research agenda', Journal of public affairs, 2012, 12, (2), pp. 109-119

[18] boyd, d.: 'Social network sites as networked publics: Affordances, dynamics, and implications.', in Papcharissi, Z. (Ed.): 'The networked self: Identity, community, and culture on social network sites' (Routledge, 2010), 39-58

[19] Faraj, S., and Azad, B.: 'The Materiality of Technology: An Affordance Perspective', in Leonardi, P.M., Nardi, B.A., and Kallinikos, J. (Eds.): 'Materiality and organizing: Social interaction in a technology world' (Oxford, 2012), pp. 237-258

[20] Gibbs, J.L., Rozaidi, N.A., and Eisenberg, J.: "Overcoming the "ideology of openness": Probing the affordances of social media for organizational knowledge sharing', Journal of Computer-Mediated Communication, 2013, 19, (1), pp. 102-120

[21] Reinhold, O., and Alt, R.: 'Analytical social CRM: concept and tool support', BLED 2011 Proceedings, 2011, pp. 226-241

[22] Andzulis, J.M., Panagopoulos, N.G., and Rapp, A.: 'A Review of Social Media and Implications for the Sales Process', Journal of Personal Selling \& Sales Management, 2012, 32, (3), pp. 305-316

[23] Ahuja, V., and Medury, Y.: 'Corporate blogs as eCRM tools-Building consumer engagement through content management', Journal of Database Marketing \& Customer Strategy Management, 2010, 17, (2), pp. 91-105

[24] Haythornthwaite, C.: 'Strong, Weak, and Latent Ties and the Impact of New Media', The Information Society, 2002, 18, (5), pp. 385-401

[25] Stephens, K.K., and Davis, J.: 'The social influences on electronic multitasking in organizational meetings', Management Communication Quarterly, 2009

[26] Watson-Manheim, M.B., and Bélanger, F.: 'Communication media repertoires: Dealing with the multiplicity of media choices', MIS quarterly, 2007, pp. 267-293

[27] Lau, H., Chin, K., Pun, K., and Ning, A.: 'Decision supporting functionality in a virtual enterprise network', Expert Systems with Applications, 2000, 19, (4), 261-270

[28] Pauleen, D.J., and Yoong, P.: 'Facilitating virtual team relationships via Internet and conventional communication channels', Internet Research, 2001, 11, (3), pp. 190-202

[29] Leonardi, P.M.: 'Digital materiality? How artifacts without matter, matter', First Monday, 2010, 15, (6)

[30] Johnson, J.S.: 'Qualitative sales research: an exposition of grounded theory', Journal of Personal Selling \& Sales Management, 2014, pp. 1-12

[31] Eisenhardt, K.M.: 'Building theories from case study research', Academy of management review, 1989, 14, (4), pp. 532-550

[32] Glaser, B.G.: 'Conceptualization: On theory and theorizing using grounded theory', International Journal of Qualitative Methods, 2008, 1, (2), pp. 23-38

[33] Miles, M.B., and Huberman, A.M.: 'Qualitative data analysis: An expanded sourcebook. 1994', Beverly Hills: Sage Publications, 1994

[34] Cohen, J.: 'A coefficient of agreement for nominal scales', Eduational and Psychological Measurement, 1960, 20, pp. $37-46$

[35] Kovacs, R.: 'Relationship building as integral to British activism: its impact on accountability in broadcasting, Public Relations Review, 2001, 27, (4), pp. 421-436

[36] Avery, E., Lariscy, R., and Sweetser, K.D.: 'Social media and shared - or divergent-uses? A coorientation analysis of public relations practitioners and journalists', International journal of strategic communication, 2010, 4, (3), pp. 189-205

[37] Hallahan, K.: 'Organizational-public relationships in cyberspace', in Hansen-Horn, T., and Dostal Neff, B. (Eds.): 'Public relations: From theory to practice' (Pearson, 2008), pp. 46-63

[38] Park, H., and Reber, B.H.: 'Relationship building and the use of Web sites: How Fortune 500 corporations use their Web sites to build relationships', Public Relations Review, 2008, 34, (4), pp. 409-411

[39] Kietzmann, J.H., Hermkens, K., McCarthy, I.P., and Silvestre, B.S.: 'Social media? Get serious! Understanding the functional building blocks of social media', Business horizons, 2011, 54, (3), pp. 241-251

[40] Ledford, C.J.W.: 'Changing channels: A theory-based guide to selecting traditional, new, and social media in strategic social marketing', Social Marketing Quarterly, 2012, 18, (3), pp. 175-186 